\title{
THE USE OF VIDEOTAPE IN FOREIGN LANGUAGE INSTRUCTION:
}

\section{A SURVEY}

\section{William Odom, University of Southern Mississippi}

In these times of shrinking enrollments, with attitudes toward language study ranging between indifference and hostility, we are well advised to seek ways to enhance the appeal of our discipline. Indeed, the articles in our journals, even those traditionally oriented toward literature, are questioning every aspect of language teaching and suggesting modifications designed to improve the effectiveness of our techniques and materials.

We are long past expecting a panacea in the form of a single device or a single method, if in fact we ever did believe in such a thing. We know that the successful program will be a delicate orchestration of teacher, text, and audiovisuals and that each of these components must be developed to the highest professional degree.

The demise of the language lab is documented, the antipathy of students toward it noted. Yet a number of us. still feel that the concept is sound, that it should be possible to expose the students to native speakers outside the classroom and to elicit responses in a controlled environment without bringing on terminal boredom or rampant paranoia. The failure of the language lab can be traced to two fundamental problems: 1) the student, isolated in his cubicle with a disembodied voice, feels alienated and apprehensive and, more important, is being treated to only a partial language experience; 2) almost universally, the tapes are beset by a funereal sobriety which would be soporific to even the most ardent proponents of the lab.

It was to attack these problems that I began almost six years ago to experiment with videotape. That problem 1 was solved was clear from the outset. The picture provided the missing elements of the total language experience. But, equally important, the students were accustomed to the medium and to gleaning information from it; they were secure with it and entertained by it.

The solution of problem 2 is more complex. The addition of picture to even mediocre material is an improvement. In-house videotape productions by students evoke greater interest and participation than the professional sound tapes accompanying textbooks. Still needed, however, are lively videotape production with a pedagogical orientation. A few notable attempts have been made, and these will be discussed later.

Those new to the field of videotape will doubtless ask, Why videotape instead of $16 \mathrm{~mm}$. film? Quite briefly, raw tape costs much less than raw film; there are no developing costs; editing is done electronically, which produces no waste as with film; a videocassette is as easy as a sound cassette, whereas film is awkward; the entire assembly may be wheeled 
around on a cart and set up anywhere, whereas problems of lighting and screens affect film; tape lasts much longer and does not break as easily as film. And the list goes on.

To find how aceptable videotape is to members of the profession and to determine the extent to which it is being used, I conducted a survey in the spring of 1975 of all four-year and two-year colleges in the country offering two or more foreign languages. To 1835 questionnaires mailed, 632 responses were received, a return of just over a third. The majority of the larger institutions responded and it is certain that nearly all those actively involved with videotape replied. The sampling is substantial enoungh to assist several groups in making decisions. Departments not currently using videotape can determine whether the activity in the field and the versatility of the medium are sufficient to warrant purchasing cquipment. Those involved with viedotape can compare notes, expand their scope and discover areas in which exchange and cooperation are possible. Finally, publishers who might be considering videotapes to accompany textbooks can gain hard inforamtion about their potential market.

The survey was broken down into questions concerning 1) equipment, 2) its use, and 3) the acceptability of videotape. The inforamtion on the questionnaires was fed into a computer and the following results were obtained. Because of multiple answers and answers left blank, the totals are not precisely consistent.

\section{Equipment}

1. Access. Of the respondents, 521 or $82.4 \%$, have access to videotape equipment; 102 do not; 9 did not answer.

2. Ownership. The great majority of departments, 435 , have access to the VT equipment of the campus audiovisual center. Only 62 own their own and 63 have access to equipment from other sources such as another department of division. 43 departments have access to more than one sources.

3. Color. 450 departments have access to black-and-white equipment, 178 to color; of these, 111 have access to both.

4. Cassette. 196 respondents have access to cassette equipment, 411 to reel-to-reel units; 117 have access to both types.

5. Camera. 477 departments have access to a camera; 45 do not. Use

1. Time. Of the 521 respondents having access to equipment, 280 do not use it. Of the 241 who do use it, 209 use it up to 5 hours per week; 19 use it between 5 and 10 hours per week; and 13 use it more than 10 hours per week.

2. Level. 124 departments use the equipment at the elementary level, 116 at the intermediate level, 101 in conversation classes, 35 in literature classes, 112 in methods classes, and 21 in other appliactions. These include culture and civilization courses, micro-teaching, linguistics, film studies, 
orientation for study abroad, drama workshops, FLES, conferences, and club activities.

3. Location. The equipment is used by $\mathbf{1 8 2}$ respondents in the classroom and by 82 in the language lab.

4. Tape production. Of those utilizing the equipment 102 have made at least one live tape which is a permanent part of their course structure; 130 have not.

5. Dubbing. Only 14 of those using VT have added foreign language narration to shows or commercials taped from American TV; 219 have not.

6. Student skits. 123 users have taped student skits for playback and commentary; 119 have not.

7. Interviews. 61 users have taped interviews with native speakers, while 175 have not.

8. Plays. 35 departmnets using VT have taped a live professional performance of a play; 198 have not.

9. Tape sharing. Of those actively using the equipment, 32 have tapes in their collections which they feel would be of use to other universities and which they are willing to have copied (187 do not). Among the subjects available are: Spanish for nurses, Hebrew, teaching German prepositions, interviews, simulated conversations, bilingual methods, EI Espanol Paso a Paso por Television (60 30-min. tapes), geography of France, Proust, student productions of a number of plays and fables, beginning courses in German and French, Chinese writing, Czech, French pronunciation, etc.

10. Commercially-produced tapes. In response to the question "Do you have or know of any commercially available tapes suitable for language instruction, other than teacher traiining tapes?" 52 respondents provided the names of publishers and distributors. Upon inquiring, the great majority of these turned out to handle only film strips, $16 \mathrm{~mm}$. film, and sound casettes. There are, however, a handful of organizations which distribute a few videotapes for language instruction (almost exclusively for Spanish and French). The most promising of these is the New York State Education Department in Albany, which can make arangements with institutions outside the state for dubbing its tapes. Of course, EMC in St. Paul, Minesota has the BBC Spanish series Zarabanda. Time-Life Multimedia also has Zarabanda (with higher rates for purchase, the same rates for rental) as well as Tout Compris. Time-Life is also issuing a French series called Ensemble. National Instructional Television, with headquarters in Bloomington, Indiana, has the VT series En Francais. GPN in Lincoln, Nebraska, the University of Michigan, VCA in Washington, and the University of Minesota also have some tapes available. These will all be discussed at length in a later article. The International film Bureau can also make some of its matreials available on videotape by special request. 


\section{Acceptability}

Having established the extent and manner of use of videotape, I next attempted to determine from all the respondents their attitude toward the potential of the medium in our profession. It was here that the computer was invaluable; it was possible to determine in a short time how many of those who responded to a particular question or series of questions answered a given question in this section. Such a task would have been unthinkable if executed manually.

1. Other media. In response to whether the department used other media on a regular basis, the results were: $16 \mathrm{~mm}$. film $-379 ; 8 \mathrm{~mm}$. Film 59; film strips-341. For those departments who have no access to VT equipment, the results were: $16 \mathrm{~mm}$. film $-45 ; 8 \mathrm{~mm}$. film -5 ; film strip - 46 .

2. Motivation. The question "Do you think that motivation can be enhanced by the variety of situations which videotape can bring to the classroom?" was answered in the affirmative by 534 respondents, in the negative by 32 . Of those who have access to equipment but do not use it, 227 replied yes, 18 no. Of those who do not have access to equipment, 74 replied yes, 8 no.

3. Comprehension. To the question "Do you think that comprehension can be increased by the realistic appearance of productions on videotape or film?" 539 answered yes, 21 no. Of those who have access to equipment but do not use it, 232 replied yes, 9 no. Of those who do not have access to equipment, 79 replied yes, 7 no.

4. Interest in equipment purchase. Question 4 reads: "If you do not have access to videotape equipment, would you be interested in having your institution acquire videotape equipment for your use (a basis system costs around $\$ 1500-\$ 2500)$ ? " Of those who have no access, 48 answered yes, 38 answered no. In addition, 55 departments who have access to equipment indicated they would be interested in having equipment specifically for their use.

5. Effect of commercial tapes. Question 5 asks: "Would your interest in videotape be increased if more commercially-produced tapes were available, especially as part of an integrated course?" To this $\mathbf{4 7 8}$ answered yes, 67 no. Of those who have access to equipment but do not use it, 210 replied yes, 27 no. Of those who do not have access to equipment, 72 replied yes, 16 no.

6. Budget. Question 6: "If videotape became an intergal part of your program, approximately how much could you afford to spend annually for tapes?" The response was: less than $\$ 100-125 ; \$ 100-\$ 300-229$; $\$ 300-\$ 500$ - 99; more than $\$ 500$ - 49. For those who have access to equipment but do not use it, the following results were obtained: less than $\$ 100-63 ; \$ 100-\$ 300-112 ; \$ 300-\$ 500-42 ;$ more than $\$ 500-16$. For those who do not have access to equipment: less than $\$ 100-23 ; \$ 100$ 30 - 40; $\$ 300-\$ 500-6$; more than $\$ 500$ - 3 . 


\section{Conclusion}

This survey of a significant number of the four-year and two-year colleges in the country offering two or more languages offers some important insight into the current uses of videotape in teaching foreign languages and the attitudes of the profession toward its potential.

Assuming that those indicating active use of videotape comprise almost the entire number of departments thus involved, it is seen that only about $15 \%$ of the foreign language departments in the country are integrating videotape into their programs. On the other hand in excess of $80 \%$ of the departments have access to the equipment, and of those who do not, about half indicate they would like to have it. Furthermore, the overwhelming majority indicate that they believe videotape can enhance motivation and comprehension. The great majority also indicate they would be more interested if more commercial tapes were available. That foreign language departments are genuinely interested in the moving picture is corroborated by the fact that almost $75 \frac{1}{2}$ of them currently use films and-or film strips. The interest is not purely hypothetical: $75 \%$ of those responding can spend in excess of $\$ 100$ a year for tape.

It would appear that the implications of the survey are clear. The International Education Project of the American Council on Education, in its Education for Global Interdependence: A Report with Recommendations to the Government-Academic Interfact Committee, specifically calls for better utilization and adaptation of available technologies, such as videotape and the computer, to the needs of language instruction. Journal articles on videotape are appearing more and more regularly. Mention of videotape in articles not dealing primarily with its utilization indicate that it is increasingly being taken for granted by our professon.

We have demonstrated a need, access to the equipment, interest, and financial feasability. We should now encourage our profession organizations to conduct workshops and call for papers on the use of videotape at both the regional and national levels. VT has great potential in the classroom with or without commercial tapes. But we should also let our publishers know that we would be interested in seeing videotapes produced where now only sound tapes are available.

Videotape cannot compensate for a bad text or a dull instructor, but it can give language study a boost at a time when it sorely needs it. Appendix

Below are listed selected comments from the questionnaire, both positive and negative, to give the reader a broader picture of the opinions of his colleagues than the admittedly biased view of the author.

....I sincerely hope you can promote the use and availability of videotape for foreign language classse. There is truly a great need.

..... (We) are considering the possibility of putting on videotape some of the situations that appear in our present elementary text. We would use 


\section{Videotape Survey}

our own majors and - depending on many factors - have them learn and speak the dialogue material. If this should be unsatisfactory, we would have them go through the motions and dub the sound track from the tapes we have from the publisher.

....I personally feel that if a text appeared with videotapes as an integral part of the program it would be an immediate success - assuming that interested schools would have the wherewithal to purchase the tapes (that may be an unwarranted assumption).

.... We feel quite constrained by the lack of materials and reliable information. Please do not interpret our many positive answers as representing any degree of sophistication. We are as yet at a very elementary stage of operation.

.... The entire writing course for Chinese I-IV has been taught through color video cassettes and the result has been most satisfactory.

....Playback facilities (video carrells or classrooms) are generally expensive but since they can be shared by the entire campus, it is, in reality, much cheaper than the traditional "language lab."

.....A mechanical operation might prove a weakening or distracting link between professor and the numerous uncertain students who need the fully humanizing influence of face-to-face, person-to-person teaching and closely supervised group testing and recitation.

.... We would definitely be interested in the availability of videotaped materials, and would be able to utilize them, particularly as we are currently planning the institution of self-paced learning programs as an option for the first two years of study in our major languages.

.... Most films (and the few available video tapes) are not geared to the language-learning situation. I have tried various things - as have other teachers - but have pretty much written off these visual media. They are too expersive for the meager help they provide.

....We expect to have the former president of Peru, Dr. Fernando Belaunde-Terry, on campus in March. It would be very useful to have his lecturers on videotape for future use. I think I'll try it.

....All of this is a utopian dream for a small private liberal arts college.

.... Its potential is as great as the professor's imagination and ambition. Using media always takes some extra work at first.

....My experience with films, tape and filmstrips, so-called "integrated" with a textbook is that it is more propaganda than help in teaching, with a cost far in excess of its value. From my point of view, TV or video tapes would have to be short ( $3-7 \mathrm{~min}$.) and not necessarily "integrated" with anything but for use as a teaching supplement when needed and appropriate.

.... Acceptability presupposes positive attitudes of faculty.

....We would like to obtain "critical incident" films in foreign language classrooms. 
Video-tape budget is almost exclusively centered in AV Center and to date they have been generally supportive of our requests.

.... I am planning to individualize Elementary German on the basis of Guten Tag. I have applied for a grant for this summer to produce individualized materials, parts of which I want to videotape. We are now planning to work out ten minutes segments for the more difficult German sounds.

.... There is no doubt that videotape can be a powerful force in a classroom, provided that it is used to reinforce course materials which are carefully and scientifically organized according to sound linguistic and psychological principles, the participants recorded on the tape are native speakers, the situational contexts taped are authentically native, there is a provision for adequate oral practice of structural drills, and opportunities for encoding practice as well, accompanying course materials provide mnemonic reinforcement with written homework.

....While $I$ as very interested in the use of videotape, the commerciallyprepared tapes will have to be of a quality comparable to the good films. "Educational" video tapes can be just as bad as "Educational" films.

.... If the videotape is similar to the audio tapes that are available with the general run of college language text books, I would have to say, "I pass."

.... If you are planning to produce such a program, as your questionnaire suggests, then be different and add humor, realism, excitement and visual quality to it.

....We have introduced an optional track of beginning language instruction in rFench, German, and Spanish which is completely audio-visual. The textbook has been replaced by $16 \mathrm{~mm}$. film. We are developing our own slides to correspond with the film vocabulary and are complementing the films with videotape grammar presentations, drills, skits, etc. As far as motivation goes, we experienced a $15 \%$ enrollment increment one year after introducing this program.

Several younger members of the foreign language department here and myself, are convinced that videotape will in time become our most effective tool. My conviction is based on a background as a filmmaker, and also on personal experience in learning Spanish: by listening to a Mexican television station in Los Angeles in 1970, I achieved perfect comprehension of spoken Spanish in less than two months.

I am very glad to hear of others' interest in this field. The more of us there are, the sooner we can stimulate both commercial production and, perhaps, an exchange of foreign language videotapes produced by ourselves at our various campuses.

. All these extras are nice, but study is the sine qua non of languagelearning. Still and moving pictures often distract students from the sound, pronunciation, and spelling of words. 
I am old-fashioned enough to think that words have some connection with language.

In many ways the "visual" part of A-V aids is the swindle of the eon. But one lives in hope $-I$ have nothing but admiration for the intent of A-V enthusiasts. I happen to regard study as hard work that should be done with sweat and tears. Education is not a show. If they want a show, let them go to the cinema.

We have studied plays with the sound-track recorded and available in the language lab and subsequently seen the film and discussed it. You can guess - when the movie becomes work instead of an escape, its popularity plummets.

.... Use of videotape is greatly enhanced by students seeing and commenting their own performance.

.. Teachers should stay off videotape.

....A mediocre program can do more harm than good.

.... High quality amateur videotapes require substantial amounts of actor and technician time, something many departments would have difficulty providing.

It is especially useful in our in-service FLES methods courses for the French-English bi-lingual elementary school programs in our area. .... (from a VT user) In no way does videotape instruction replace classroom teacher (live) instruction . . . it is supplementary, a very useful tool to supplement, to motivate, to review, to introduce cultural elements, etc. .... The reception was enthusiastic, and numerous professors said they hoped to make extensive use of the equipment. Since then the equipment has been gathering dust in the language laboratory... The rather elaborate plans of the language professors to tape model classes, etc. were still-born. ....We have developed in-house a 10 part Spanish grammar videotape cassette series and are working on similar programs for French and German. ....All one needs for language teaching is: 1) a competent teacher, 2) a good book, 3) an intelligent student. The rest is simply very expensive empire building.

....Its advantages don't seem to be getting the kind of publicity they deserve.

.... If videotape in the language area goes commercial, the greatest threat is that the format which is introduced will become, as in audiotape, a rather inflexible model of dubious perfection.

....We have to learn that these things are only tools and it is what we produce with the tool that counts, not the tool itself.

....I have been helping the University of Wisconsin Center System (2-year) campuses make a videotaped first-year course for their campuses which have no French instructor.

....We have been very pleased with the one set of tapes we've developed. 
...We don't use the videotape equipment we have because our teachers find it difficult to operate, time-consuming, and in general, not worth the trouble.

....Are you hustling this videotape as a profit?

A great number of respondents reiterated their conviction that the potential of VT is great and said that they had been inspired to investigate further the possibilities of using it. Some said they would increase their budget requests, others complained that extremely tight budgets would prohibit thęir using the medium.

The comments showed that the respondents are generally enthusiastic about VT, want to know more about it, are very eager for high quality professional tapes, and wish to be kept informed of developments in the area.

At this time, the University of Southern Mississippi is seeking grant money to establish a lending library for the purpose of disseminating free of charge the tapes which many universities are willing to share.

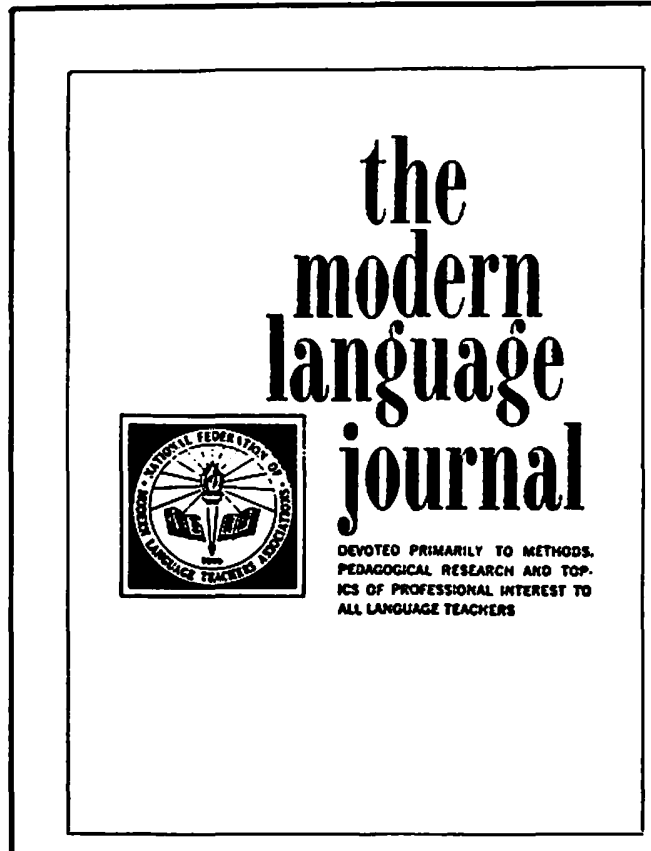

"The outstanding journal of modern language teaching in the United States" stimulating articles pedagogical research reviews of textbooks and teaching aids useful bibliog. raphies timely announcements current advertisements

Edited by Charles L. King, The University of Colorado, Boulder, Colorado. Published by The National Federation of Modern Language Teachers Associations.

Six issues a year (September through April) . . . individual subscription $\$ 7.00$, institutions and foreign subscriptions $\$ 8.00$ (net in USA funds). Sample copy on request.

The Modern Language Journal Wallace G. Klein, Business Manager 13149 Cannes Drive St. Louis, Missouri 63141 